\title{
COMMENTARY
}

\section{Optimal surgical strategies in living kidney donation}

\author{
Omar Ali, MD; ${ }^{11}$ Alp Sener, MD, PhD, FRCSC ${ }^{1,2}$
}

Division of Urology and 2Department of Microbiology and Immunology, Western University, London, ON, Canada

Cite as: Can Urol Assoc J 2016;10(7-8):258-9. http://dx.doi.org/10.5489/cuaj.4037

See related article on page 253.

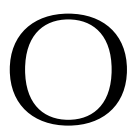
$f$ the various options for patients with end-stage renal disease, kidney transplantation is the treatment of choice. Living donor nephrectomy has made a significant impact in addressing the shortfall in suitable cadaveric kidneys available for transplantation. ${ }^{1}$

Live donor renal transplantation offers significant advantages compared with cadaveric donor transplantation, including increased graft and patient survival, diminution in incidence of delayed graft function, acute tubular necrosis, and reduction in waiting time. Notwithstanding these gains, live donors continue to be underused and account for only approximately one-quarter of all renal transplants performed in North America. ${ }^{2}$

Open donor nephrectomy (ODN) for live donor kidney transplantation is a safe procedure that has been used for more than 30 years with excellent results. Laparoscopic donor nephrectomy (LDN) is a relatively newer technique that has the potential of decreased postoperative pain, less incisional morbidity, and shorter recovery time. Furthermore, it has clearly been demonstrated that the advent of LDN has led to a tremendous increase in the number of live donors globally. ${ }^{3}$

Since it was first described in the 1990s, conventional LDN has been the standard of care at most major transplant centres. Clayman et al described the first successful conventional laparoscopic nephrectomy in 1991 for intrinsic renal disease. Several years later, a laparoscopic donor nephrectomy procedure was successfully performed in a large animal model, while Ratner and colleagues described the first successful conventional laparoscopic live donor nephrectomy one year later. Donors were discharged home within two days and most returned to work within two weeks postop- eratively. Moreover, recipient outcomes were significantly better than deceased donor allografts. ${ }^{4}$

The disincentives of ODN by standard flank approach are important reasons for development of laparoscopic surgery. However, due to the relatively steep learning curve of LDN, especially in the face of negative consequences to the living donor, several centres have adopted a mini-incision ODN (mini-ODN) to minimize the morbidity of ODN. Few reports of mini-open procedures have been published with smaller incisions, shorter lengths of stay, and less analgesic, reflecting the ability to reduce apparent morbidity, compared to standard ODN. ${ }^{5,6}$

The authors of the current article "Back-to-back comparison of mini-open vs. laparoscopic technique for living kidney donation" demonstrate that despite a longer surgical time and higher upfront cost, their study supports that LDN yields several advantages over the mini-ODN procedure, including a lower estimated blood loss, fewer intraoperative complications, and shorter length of hospital stay, all while maintaining excellent renal allograft outcomes.

As highlighted by the authors, there are only few studies comparing laparoscopic and mini-incision approaches for living donor nephrectomy. In a prospective, single-blind, randomized, controlled clinical trial comparing LDN to mini-ODN, Kok et al demonstrated that LDN results in a better quality of life compared with mini-incision open donor nephrectomy, but equal safety and graft function. The study also showed that LDN resulted in longer skinto-skin time, longer warm ischemia time, less blood loss, and a similar number of complications. After laparoscopic nephrectomy, donors required less morphine and shorter hospital stay. At the one-year followup mark, mean physical fatigue was less and physical function was better after laparoscopic nephrectomy. Function of the graft and graft survival rate of the recipient at one year censored for death did not differ. ${ }^{7}$ In an earlier study, Perry et al demonstrated that quality of life, postoperative pain, and return to normal 
activities following LDN were significantly improved compared to the mini-ODN. ${ }^{8}$

Despite the retrospective and multisurgeon perspective of the current manuscript, the authors make a significant contribution to what is currently known in the literature regarding these two differing approaches to living donation surgery. Future studies looking at: (1) the total economic impact between the two procedures, especially given that the LDN group appears to return to work sooner than the mini-ODN cohort; and (2) whether shifting from mini-ODN to LDN leads to a positive impact on the attitudes and willingness towards donation in living donors, would be of considerable interest to transplant centres.

We are in agreement with the authors that LDN should be the gold standard in living donation, as it clearly provides an attractive and safe option for living donors, as long as the transplant centre has the expertise in laparoscopic surgery. As the number of urologists involved in transplantation is decreasing across North America, having a strong foothold in LDN procedures is sure to keep interested urologists as absolutely integral members of the transplant team. All urology programs should make concerted efforts in training both residents and fellows in performing LDN operations safely and efficiently, as this potential source of transplantable kidneys continues to remains a focus of expansion for many transplant centres across the world.
Competing interests: Dr. Ali reports no competing personal or financial interests. Dr. Sener has received grants from Eli Lilly, Conmed, and FirstKind; and is the co-founder of and holds a patent for a product marketed by Clearwater Clinical Limited.

\section{References}

1. Gupta N, Raina P, Kumar A. Laparoscopic donor nephrectomy. J Minim Access Surg 2005; 1:155-64.

2. Shafizadeh S, McEvoy JR, Murray C, et al. Laparoscopic donor nephrectomy: Impact on an established renal transplant program. Am Surg 2000;66:1132-5.

3. Skrekas $G$, Papalois VE, Mitsis $M$, et al. Laparoscopic live donor nephrectomy: A step forward in kidney transplantation? JSLS 2003;7:197-206.

4. Cheguevara Afaneh, Meredith J. Aull, Joseph J. Del Pizzo, Sandip Kapur. Chapter 13 open access. In: Surgical Advances in Laparoscopic Donor Nephrectomy. Current, book, 2012.

5. Modi P. The mini-incision donor nephrectomy is best suited for Indian patients undergoing live donor nephrectomy: Against the motion. Indian J Urol 2010;26:142-4. http://dx.doi.org/10.4103/09701591.60465

6. Neipp M, Jackobs S, Becker T, et al. Living donor nephrectomy: Flank incision vs. anterior vertical mini-incision. Transplantation 2004;78:1356-61. http://dx.doi.org/10.1097/01.TP.0000140975.96729.A7

7. Kok NF, Lind MY, Hansson BM, et al. Comparison of laparoscopic and mini incision open donor nephrectomy: Single blind, randomized, controlled clinical trial. BMJ 2006;333:221. http://dx.doi.org/10.1136/ bmi.38886.618947.7C

8. Perry KT, Freedland SJ, Hu JC, et al. Quality of life, pain and return to normal activities following laparoscopic donor nephrectomy vs. open mini-incision donor nephrectomy. J Urol 2003;169:2018-21. http://dx.doi.org/10.1097/01.ju.0000067975.59772.b6

Correspondence: Dr. Alp Sener, Division of Urology and Department of Microbiology and Immunology, Western University, London, ON, Canada; alp.sener@|hsc.on.ca 